\title{
313
}

\section{Relações públicas em jogo: a simulação como recurso didático}

Game of public relations: simulation as a teaching resource

Relaciones públicas en juego: la simulación como recurso didáctico

Márcio Simeone Henriques

- Pós-doutor pela Universidade Nova de Lisboa, Portugal, com bolsa da Capes

- Doutor em Comunicação pela Universidade Federal de Minas Gerais (UFMG)

- Mestre em Educação pela Universidade Federal do Rio de Janeiro (UFRJ)

- Professor do Departamento de Comunicação Social da UFMG

- E-mail: simeone@ufmg.br

\section{Daniel Reis Silva}

- Doutorando do Programa de Pós-Graduação em Comunicação Social da Universidade Federal de Minas Gerais (UFMG)

- Mestre em Comunicação Social e bacharel em Relações Públicas pela UFMG

- E-mail: daniel.rs@hotmail.com.br 


\section{Resumo}

0 artigo aborda a experiência do "Jogo das relações públicas", uma atividade lúdica de simulação e interpretação de papéis concebida para auxiliar a compreensão acerca das complexas dinâmicas que permeiam a atividade de relações públicas. Discorre-se sobre a relação entre jogos de simulação e ensino, bem como sobre características da área de relações públicas que tornam propício um jogo sobre a atividade. Em seguida, apresenta-se o jogo e se discutem seus elementos e fundamentações teóricas, abordando ainda aspectos da avaliação do jogo.

\section{PALAVRAS-CHAVE: RELAÇÕES PÚBLICAS・PÚBLICOS • OPINIÃO PÚBLICA • ENSINO・JOGOS DE SIMULAÇÃO.}

\section{Abstract}

The article addresses the experience of the "Public relations game", a gaming simulation and role-playing activity designed to assist with the understanding of the complex dynamics that permeate the public relations activity. The connection between simulation games and teaching is assessed and also the characteristics of the public relations area that enable developing a game on the activity. Subsequently, the paper presents the game and its elements and theoretical grounds are discussed, also addressing the game assessment aspects.

\section{KEYWORDS: PUBLIC RELATIONS • AUDIENCES • PUBLIC OPINION • TEACHING • SIMULATION GAMES}

\section{Resumen}

El artículo aborda la experiencia del "Juego de las relaciones públicas", una actividad lúdica de simulación e interpretación de papeles diseñada para ayudar a la comprensión de las complejas dinámicas que impregnan la actividad de relaciones públicas. Apunta la relación entre los juegos de simulación y educación, así como los factores del ejercicio del área de las relaciones públicas que tornan ese juego una actividad didáctica adecuada a la formación profesional. A continuación se presentan todos los elementos del juego, y se discuten sus fundamentos teóricos, así como se abordan sus métodos de evaluación. 
A utilização de jogos educacionais, que visam promover o engajamento e o aprendizado por meio de atividades lúdicas, tornou-se recorrente nas últimas décadas. Atualmente, os jogos são reconhecidos como um recurso educacional importante, sendo empregados em situações diversas, como a socialização de crianças em fases pré-escolares (Brougère, 1998) ou mesmo treinamentos bastante específicos para gerentes empresariais em posições de liderança (Ramos, 1991).

No presente artigo, refletimos sobre a experiência do desenvolvimento e aplicação de um jogo para auxiliar o ensino de relações públicas, batizado de "Jogo das relações públicas". Uma versão-piloto do jogo foi integrada entre 2013 e 2016 à disciplina Técnicas e Processos de Relações Públicas do Curso de Graduação em Comunicação Social da Universidade Federal de Minas Gerais (UFMG), e consiste em uma atividade lúdica de simulação e interpretação de papéis, na qual os participantes devem, no decorrer de cinco semanas, interagir uns com os outros para lidar com um cenário problemático apresentado. A dinâmica visa fomentar uma maior compreensão acerca dos principais desafios da atividade de relações públicas, em especial os conflitos resultantes da diversidade de interesses e grupos na sociedade contemporânea, a complexidade das situações enfrentadas pelos profissionais da área e a influência da mídia na formação da opinião e dos públicos.

Apresentamos inicialmente uma discussão a respeito da utilização de jogos como recursos didáticos e da definição e importância da ideia de simulação que justifica a realização da proposta, além de argumentarmos pela relevância do emprego de atividades de simulação no ensino das relações públicas. Em seguida abordamos os elementos e a dinâmica do "Jogo das relações públicas", refletindo sobre os principais fundamentos teóricos presentes na atividade e destacando quatro eixos centrais: a formação dos públicos e do interesse público; a movimentação dos públicos; as estratégias e ações de relações públicas; e a ação da mídia. Finalmente, concluímos o presente artigo discutindo aspectos da avaliação do jogo.

\section{SOBRE JOGOS E SIMULAÇÕES}

Inúmeros teóricos se dedicaram, nas últimas décadas, a compreender a utilização de jogos para o ensino (Kishimoto, 1994; Brougère, 1998, 2002; Piaget, 1976). É importante ressaltar a observação de Brougère sobre como o jogo não deve ser caracterizado por uma "vocação particular para a educação", mas sim pelo seu potencial de transformação e construção de conteúdos: "porque manipula comportamentos e significações exteriores [a si], o jogo pode ser um espaço de aprendizagem em relação a esses mesmos conteúdos" (Brougère, 2002, p. 16). 0 autor destaca como o jogo possui a capacidade de instaurar espaços miméticos ricos, nos quais séries de conteúdos exteriores e significações culturais são retomadas e dotadas de novas acepções pelos jogadores. Justamente pela manipulação destes significados, o jogo pode ser acompanhado "de aprendizagens informais ou implicar aprendizagens anteriores para dominar esses conteúdos" (Brougère, 2002, p.16). 0 jogo se torna também, devido ao seu apelo ao divertimento e como uma quebra na rotina, uma forma de aumentar o engajamento e o entusiasmo dos estudantes (Perrotta et al., 2013).

Dentre as diversas modalidades de jogos, interessa-nos especialmente refletir sobre os jogos de simulação. Cosete Ramos (1991) argumenta por uma utilização ampliada do conceito de simulação, entendendo-a como "uma seletiva representação da realidade, abrangendo apenas aqueles elementos da situação real que o autor considera relevante para seu propósito" (Ramos, 1991, p. 21). A simulação consiste, assim, em uma representação simplificada da realidade (ABT, 1974), uma abstração propícia para abordar processos dinâmicos e complexos.

Os jogos de simulação colocam os jogadores frente a um recorte simplificado da realidade a partir do qual eles "assumem papéis realistas, enfrentam problemas, formulam estratégias, tomam decisões, e obtêm rápida informação sobre as consequências de sua ação" (ABT, 1974, p. 12). Surgem como uma alternativa para lidar com problemas concretos, consistindo em um modelo de aprendizado orientado para a ação e centrado nos participantes, que devem tomar decisões e traçar estratégias para alcançar 
determinados objetivos. Dentre as principais vantagens do uso pedagógico dos jogos de simulação devem ser citadas também a aproximação entre teoria e prática e o incentivo para que o participante assuma um papel ativo no seu próprio aprendizado. Nessa modalidade de jogo os "indivíduos podem novamente ter participação, e pensamento e ação podem novamente ser integrados" (ABT, 1974, p. 4), aproximando-se do ideal do aprendizado ativo proposto por John Dewey (1959).

Tais características fizeram com que os jogos de simulação conquistassem reconhecimento em áreas como o treinamento militar e a capacitação de lideranças em organizações, além de serem também um recurso didático no ensino superior. William Gamson é um dos pioneiros nessa área, tendo criado, em 1964, o jogo "Simsoc - simulated society". Segundo Gamson (2013), sua intenção era encontrar uma maneira de demonstrar aos alunos a complexidade da tomada de decisões coletivas. Mais do que isso, Gamson intencionava permitir aos estudantes lidar efetivamente com questões de conflitos e com problemas de ordem social. Inicialmente aplicado em um laboratório de sociologia, o Simsoc era uma oportunidade para que os estudantes "se encontrassem em posições poderosas que poucos iriam ocupar no restante de suas vidas, lidando com dilemas, desafios e tentações" (Gamson, 2013, p. 612)'. 0 sucesso dessa experiência foi replicado em outras iniciativas similares durante a carreira do autor: o "What's news", um jogo de simulação sobre a imprensa, e o "Global justice game", que busca destacar dilemas globais, como trabalho infantil ou contaminação de águas, e prover uma variedade de ações possíveis para que os participantes tentem lidar com os mesmos.

\section{Um jogo de simulação sobre relações públicas}

Uma primeira justificativa para um jogo sobre as relações públicas reside no fato de a área lidar com processos sociais de grande complexidade. Em uma perspectiva sistêmica, observamos que o caráter mediador das relações públicas faz com que a atividade interaja com uma multiplicidade de sistemas sociais dotados de lógicas e interesses peculiares. A atividade é, assim, perpassada e configurada por diversas dimensões sistêmicas - organizacional, dos públicos e da opinião pública, midiática e governamental -, lidando com um complexo de interações e de interinfluências onde cada um dos interagentes adota estratégias e diferentes táticas de ação.

Uma questão didática importante emerge dessa característica: como gerar uma boa compreensão acerca de processos complexos como aqueles com os quais a atividade lida? Um problema surge da observação de que nem sempre é possível obter tal entendimento apenas por meio da literatura, reconhecendo as dificuldades e limitações dos esforços de descrição e explicação das múltiplas e interconectadas lógicas que perpassam as dinâmicas de relações públicas. Mesmo o recurso didático aos estudos de caso possui limitações significativas para prover uma compreensão refinada acerca da complexidade dos processos da atividade, enfrentando constrangimentos devido ao próprio caráter estratégico das relações públicas, que limita 0 acesso aos dados sobre as decisões de organizações e aos materiais a serem estudados. Além disso, o tom unilateral do relato tende a omitir os aspectos contraditórios das questões envolvidas. Mesmo casos premiados sofrem de escassez de informações, impossibilitando um estudo aprofundado sobre os seus diversos elementos. Mais ainda, o pensamento centrado na organização (um vício também compartilhado por parte da literatura da área) inviabiliza a exploração de uma visão global sobre as relações públicas, falhando em captar interconexões e influências de grande importância para a compreensão de momentos críticos no decorrer de uma controvérsia pública.

Diante de tais limitações, a proposta de desenvolvimento de um jogo de simulação surge como promissora. Como mencionado, uma das principais características desses jogos consiste na exploração de situações complexas e problemas concretos. 0 recurso da simulação oferece ainda uma oportunidade de quebrar a visão centrada na organização, recorrente no ensino de relações públicas. Acreditamos, ainda, que a proposta possibilite o desenvolvimento de habilidades e capacidades relevantes

1 Tradução nossa. 
para um profissional da área. Ao colocar os participantes em um papel ativo no qual devem traçar estratégias visando alcançar certos objetivos (tanto no lado das organizações como no lado dos públicos), oferece a oportunidade para que os estudantes possam desenvolver suas capacidades de tomada de decisão e de lidar com situações críticas, compreender e avaliar dilemas morais, bem como trabalhar habilidades de expressão, de argumentação e exposição pública.

\section{O CENÁRIO E A COMPOSIÇÃO DO JOGO}

Como Abt (1974) menciona, a concepção de um jogo de simulação perpassa a tomada de decisão sobre sua complexidade, algo diretamente vinculado aos objetivos didáticos almejados. Apesar de uma simulação ser sempre uma representação simplificada da realidade, é importante refletir sobre o ponto em que a simplificação excessiva passa a suprimir nuances importantes e a comprometer o entendimento sobre os diferentes elementos interconectados daquela situação. No caso do "Jogo das relações públicas", que busca propiciar maior compreensão acerca da multiplicidade de lógicas que perpassam os processos da atividade, uma primeira preocupação era evitar o esvaziamento da simulação, que tornaria 0 jogo mais simples e acessível, mas prejudicaria seu potencial didático.

Em sua estrutura básica, o "jogo" consiste na simulação de um cenário problemático: uma situação conflituosa entre diversos atores sociais ancorada em elementos característicos de problemas de relações públicas. 0 primeiro cenário construído para o jogo foi intitulado "Mina Oráculo", e as premissas básicas e equipes envolvidas no mesmo são apresentadas na Tabela 1.

Tabela 1: Cenário problemático - Mina Oráculo.

\section{Cenário Mina Oráculo}

Santa Helena é um município médio de Minas Gerais. Encontra-se encravado na Serra do Arco e consiste em um dos últimos remanescentes intactos do Quadrilátero Ferrífero, no qual são encontrados biomas de Mata Atlântica, Cerrado e vegetação de canga. Recentemente, Santa Helena ganhou notoriedade nacional devido as informações de um novo projeto bilionário da Mineradora Nexus: a Mina Oráculo. 0 projeto visa a construção de uma mina no município para exploração de ferro e a expansão da malha ferroviária para o escoamento da produção. A hora do projeto parece ser propícia, com o poder público municipal apostando no mesmo como uma forma de frear a crise econômica da cidade e atrair novos investimentos.

Resumo da

situação

Porém, o projeto traz diversas controvérsias tanto pelo seu potencial impacto ambiental, problemática especialmente significativos graças aos recursos hídricos que existem na Serra do Arco, quanto também pelos impactos diretos no bairro Arcal, o mais próximo do local previsto para a mina e que teria centenas de residências desapropriadas para a construção da ferrovia, e pelas preocupações socioeconômicas decorrentes da implementação de um projeto desse porte e da própria atividade de mineração em cidades de perfil semelhante ao de Santa Helena.

O projeto gerou, assim, um cenário de incertezas, com a população de Santa Helena acompanhando com grande interesse e expectativa o desenrolar da controvérsia para apoiar ou ir contra a implementação da Mina Oráculo. 


\section{Cenário Mina Oráculo}

\begin{tabular}{|l|l|}
\hline $\begin{array}{l}\text { Equipes } \\
\text { envolvidas na } \\
\text { controvérsia }\end{array}$ & $\begin{array}{l}\text { 1) Mineradora Nexus; 2) Preferitura Municipal de Santa Helena; 3) ONG Ambiental Águas } \\
\text { de Minas; 4) ONG Internacional World Mining Watch; 5) Associação dos Moradores } \\
\text { do Bairro Arcal; 6) Associação Comercial e Industrial de Santa Helena; 7) Sindicato } \\
\text { dos Trabalhadores da Indústria de Extração de Ferro e Metais de Minas Gerais. }\end{array}$ \\
\hline $\begin{array}{l}\text { Equipes da } \\
\text { imprensa }\end{array}$ & $\begin{array}{l}\text { 1) Rede Global de Televisão (veículo nacional); 2) Jornal Minas Gerais (veículo estadual } \\
\text { de tendências conservadoras); 3) Jornal Amanhã (periódico alternativo). }\end{array}$ \\
\hline
\end{tabular}

Fonte: elaborada pelos autores.

Os participantes são divididos em equipes contendo entre três e seis membros. Cada equipe assume 0 controle de um grupo envolvido no conflito apresentado e deverá realizar uma série de ações para interferir na controvérsia, buscando atingir seus objetivos. Para trabalhar uma visão ampliada sobre as situações do mundo real, existem dois tipos de equipes: as envolvidas na controvérsia, que representam grupos diretamente relacionados com o conflito apresentado e devem realizar ações para se posicionar e influenciar no andamento das controvérsias; e as equipes de imprensa, que representam veículos jornalísticos. Cada cenário apresenta três equipes de jornalistas que possuem características próprias - alcance e tendências editoriais diferentes. Tais equipes realizam um tipo de ação específica durante o jogo: a publicação de notícias sobre o desenrolar do caso a partir da atuação das demais equipes.

Além de receber um documento contendo a explicação geral sobre o cenário, cada equipe recebe um dossiê exclusivo que explica suas características e seus indicadores de sucesso. Os indicadores são a forma de medir o desempenho de cada equipe durante o jogo, variando a cada ação realizada pelas equipes. Em geral refletem uma série de suportes de públicos específicos e da opinião pública, e sua variação será determinada pelos moderadores do jogo (em nosso caso, os professores da disciplina).

\section{A ESTRUTURA E A DINÂMICA DO JOGO}

0 desenrolar do jogo ocorre por rodadas, e pode ser compreendido pela observação que Richard Barton (1973) tece sobre a tomada de decisão em jogos de simulação, na qual a mesma ocorre numa sequência de três estágios: estímulo, reação e consequência. A partir de um estímulo lançado pelo jogo, a situação problemática inicial, solicita-se a reação do jogador, que é premido a tomar uma decisão que provoca uma consequência no ambiente do jogo, atualizando-o. 0 cenário é, assim, algo em construção, que será moldado durante o desenrolar do jogo. Sua evolução ocorrerá tanto em decorrência da ação dos participantes, que influenciam diversos aspectos da situação, como também através de novos fatores que serão introduzidos de maneira aleatória em momentos específicos - como novos grupos que se engajam na controvérsia pública, novos desenvolvimentos ou descobertas sobre a situação.

0 jogo foi concebido para ocorrer em três rodadas, que se passam em dois ambientes distintos: 0 ambiente presencial, na sala de aula, e o ambiente virtual, em um fórum previamente preparado ao qual todos os participantes tenham acesso ${ }^{2}$. A parte presencial foi idealizada para ser jogada em uma hora e quarenta minutos e consiste de quatro etapas. Inicialmente as equipes se reúnem de forma isolada para discutir o cenário e traçar estratégias para atingir seus objetivos, planejando seus

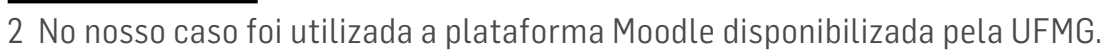


próximos passos. Em seguida, elas se reúnem com as outras, engajando-se em um processo de negociação no qual buscam formar acordos e discutir apoios para melhorar seus indicadores de sucesso. Na terceira etapa as equipes voltam a se reunir isoladamente para decidir as ações que serão executadas na rodada. Finalmente, a quarta etapa é a da ação pública, em que cada equipe realiza um pronunciamento público, à frente de todos os participantes, delineando suas ações e seus posicionamentos naquela rodada. Durante todo o tempo, as equipes de jornalistas coletam materiais, podendo dialogar com as demais equipes durante a etapa da negociação e interpelá-las durante a etapa da ação pública.

Concluída a parte presencial, as equipes envolvidas na controvérsia devem postar no fórum virtual um breve press release delineando suas ações na rodada. As equipes de jornalistas possuem, então, um prazo para postarem as notícias referentes àquela rodada no fórum virtual. Assim como na vida real, tais notícias possuem limitações sensíveis de espaço, impossibilitando que todas as ações sejam tratadas da mesma forma. Assim, as equipes da imprensa enquadram os acontecimentos, sendo as notícias por eles produzidas de grande importância por implicarem na variação dos indicadores de sucesso. Conquistar uma visibilidade positiva para o empreendimento em um veículo nacional, por exemplo, pode ocasionar um ganho de confiança do mercado e a valorização das ações da mineradora. Os moderadores do jogo assumem o papel de públicos e da opinião pública, ou seja, dos públicos em sua generalidade, avaliando, por meio das ações das equipes e de sua repercussão na mídia, as variações nos indicadores de sucesso.

Um indicativo do resultado é comunicado para as equipes no início do segundo encontro presencial, assim como atualizações no cenário e a ocorrência dos eventos aleatórios. Após três rodadas, o jogo é finalizado, e a apuração final determina a equipe com melhores indicadores de sucesso. Inicia-se o processo de avaliação do jogo, com duração de três horas. A Figura 1 apresenta uma síntese da estrutura básica do jogo:

Figura 1: Estrutura das rodadas do "Jogo das relações públicas"

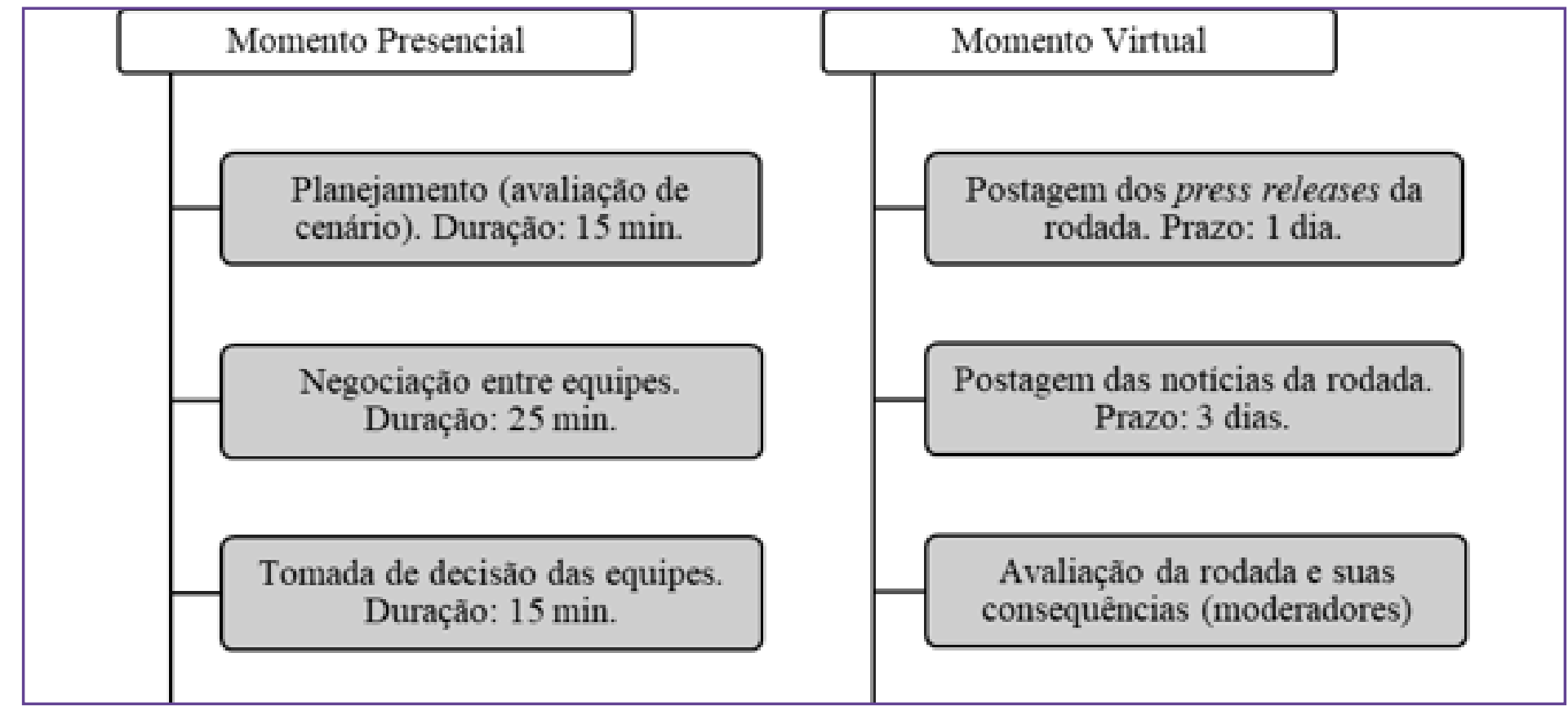

Fonte: elaborada pelos autores.

0 jogo foi concebido de forma a salientar aspectos de cooperação e competição entre as equipes, inspirado em jogos que fomentam um misto de conflito e dependência (Gamson, 2013). A principal mecânica para tanto é a variação dos indicadores de sucesso, que não depende apenas das ações realizadas por uma equipe - eles flutuam igualmente de acordo com as ações realizadas por outras equipes e, principalmente, pela forma com que a mídia tece a narrativa sobre a situação. Temos assim um cenário complexo, no qual cada equipe possui seus próprios objetivos, interesses e indicadores de sucesso. Apesar 
de o "Jogo das relações públicas" não ser de soma-zero, indicadores de diferentes equipes são por vezes contrários, com o sucesso de uma delas comprometendo os objetivos de outras (a cobertura midiática é um exemplo, já que o foco sobre as ações de determinada equipe acaba significando a negligência quanto às ações das demais e afetando seu desempenho). Por outro lado, a cooperação entre as equipes surge como uma estratégia para influenciar ações diversas, fortalecer posicionamentos e lutar por cobertura midiática. A cooperação perpassa, porém, a busca por um interesse comum entre uma ampla diversidade de objetivos contraditórios e modos de agir distintos, o que abre espaço para práticas como a barganha, a busca por um meio-termo entre certos posicionamentos e a formação de alianças estratégicas.

No decorrer do jogo, as equipes são também confrontadas com acontecimentos aleatórios, externalidades (sorteadas pelos moderadores) que afetam a todos e que podem alterar os rumos da situação, desvelando novos sentidos, possibilidades e problemas a serem enfrentados. Tais acontecimentos podem incentivar tanto a cooperação entre as equipes (no caso de uma tragédia, por exemplo) como o conflito e a competição (um vazamento de informações que revela que a organização escondia um estudo de impactos ambientais que apontava para um elevado grau de degradação ambiental, por exemplo), constituindo-se em mais um elemento que aumenta a complexidade daquelas relações.

O jogo foi concebido como uma plataforma maleável que propicia adaptações diversas e a aplicação de diversos casos. A mesma dinâmica permite a utilização de cenários problemáticos distintos, que abordem outros elementos da atividade de relações públicas ${ }^{3}$. Além disso, a natureza aberta da simulação envolvida no jogo possibilita que diferentes aplicações de um mesmo cenário se desenvolvam de maneira bastante distinta. Foi possível observar tal característica nas oportunidades em que aplicamos o mesmo cenário, com a controvérsia em cada uma delas ganhando rumos próprios nos quais diferentes equipes se destacaram e acabaram por ganhar 0 jogo ${ }^{4}$.

\section{A REFLEXÃO SOBRE O JOGO E SEUS ELEMENTOS}

Ao conceber o jogo, uma das primeiras questões sobre a qual nos debruçamos foi o momento ideal de sua inserção no programa da disciplina, que possui característica introdutória sobre os conceitos da área. Optamos por inserir a atividade em um momento intermediário, em que os alunos já tivessem contato com discussões sobre a função das relações públicas e sua importância em organizações contemporâneas, bem como uma primeira abordagem sobre formação e movimentação de públicos, opinião pública, imagem e reputação, permitindo uma referência para a ação e para recuperar os sentidos da atividade. Pela própria natureza aberta do "Jogo das relações públicas", diferentes elementos temáticos podem surgir no decorrer da atividade. Acreditamos, porém, que a essência do jogo perpassa quatro elementos que devemos abordar com maiores detalhes.

0 primeiro elemento diz respeito à formação de públicos e do interesse público. Nesse sentido, a dinâmica do jogo permite explorar a própria constituição de uma questão pública relevante, bem como a forma com que diferentes públicos se posicionam ante uma situação controversa. Duas questões de grande importância para a área se localizam no âmago desse elemento: a formação de públicos, com sujeitos que se julgam afetados perante uma controvérsia (Dewey, 1954;

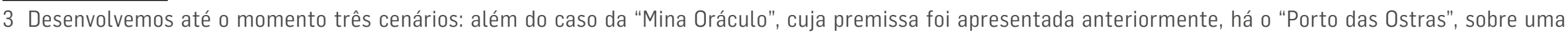

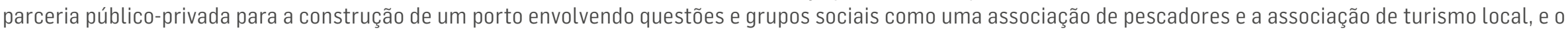
"Soja Transgênica no Paraná", sobre uma controvérsia acerca de sementes geneticamente modificadas.

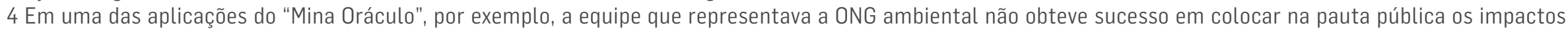

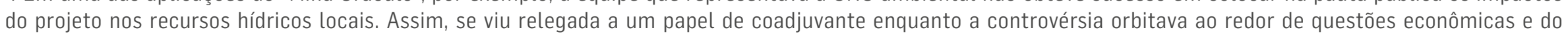

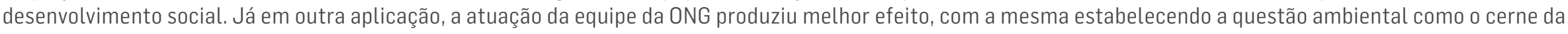
situação problemática, o que demonstra as possibilidades de desenvolvimento do jogo.
} 
Blumer, 1971), e o processo de coletivização que gera a formação de um interesse público (Henriques, 2010). No decorrer do jogo, as equipes não apenas se posicionam frente a uma situação, mas se engajam em uma disputa de sentido sobre o próprio interesse público, sustentando posições e propondo significados sobre os acontecimentos. É viabilizada, assim, uma observação sobre os processos complexos de disputa de sentido que perpassam a atividade.

Além de abordar a formação de públicos, um segundo elemento do jogo se refere à movimentação dos mesmos. 0 jogo apresenta um cenário propício para a observação do processo de mobilização de públicos menos ou mais organizados em função de uma situação controversa, permitindo ver elementos da disputa de interesses e da tentativa dos públicos de influenciar a opinião de outros em favor de certas posições. É de grande riqueza a observação sobre a complexidade de táticas desenvolvidas pelas equipes que representam grupos e movimentos sociais, que buscam conquistar apoios para suas causas por meio de atos públicos, do apelo a celebridades e especialistas e da construção de fatores de identificação. Importante notar os fatores estratégicos empregados por grupos na tentativa de conquistar visibilidade, relacionar-se com a imprensa e forjar alianças - aspectos fundamentais na literatura que aborda a mobilização social (Henriques et. al., 2004; Toro e Werneck, 2004) e que ajudam a compreender facetas da dinâmica de formação da opinião pública. Mesmo sem um background como membros de uma ONG ambiental ou de um movimento de bairro, os participantes acionam repertórios anteriores, mimetizando condutas que eles atribuem a tais grupos. Muitos jogadores, inclusive, vão atrás de informações e estratégias utilizadas em situações parecidas, ampliando a riqueza da simulação construída e permitindo abordar a movimentação dos públicos de maneira mais verossímil.

O terceiro elemento parte da observação de que o jogo também permite explorar as estratégias e ações de relações públicas empregadas pelas diversas organizações e atores institucionais, tanto na interação entre si como com os públicos. É possível vislumbrar relações de organizações com governos, comunidades, segmentos específicos e com a imprensa - aspectoschave das teorias de relações públicas e do planejamento estratégico (Kunsch, 2003). Assim, podem ser explorados os recursos e instrumentos acionados por tais atores, bem como a maneira com que são constituídas alianças estratégicas e os elementos que essas organizações incorporam em seus discursos na tentativa de lidar com uma controvérsia. Mais do que observar as táticas e estratégias das organizações e dos públicos de maneira isolada, o jogo permite refletir sobre a relação entre esses atores, explorando as diversas interações por diferentes pontos de vista.

Por fim, o quarto elemento central é a ação da mídia. As dinâmicas do jogo permitem ver a ação da imprensa e seu modus operandi, expandindo a compreensão sobre critérios de noticiabilidade, enquadramentos, alinhamentos e limitações da ação da imprensa. Mais ainda, é fundamental a observação sobre a influência da própria mídia no desenrolar da controvérsia, explorando a forma com que os diversos atores envolvidos tentam pautar a mídia ao mesmo tempo em que são pautados por ela. 0 papel das equipes da imprensa é, assim, fundamental, permitindo refletir e tecer considerações acerca de teorias sobre o agendamento e o enquadramento midiático. Assim, de um lado, a dinâmica apresentada pelo jogo possibilita refletir sobre a importância da mídia na concepção de estratégias e táticas organizacionais, bem como nas intrincadas nuances da formação da imagem e da cristalização da reputação das organizações (Baldissera, 2008). Por outro, revela também aspectos sobre a atuação da mesma nos processos de formação do público e na disputa de sentidos para determinar o que é de interesse público, questões de grande importância para a compreensão sobre movimentos sociais.

\section{PROCESSO DE AVALIAÇÃO E RESULTADOS INICIAIS}

Conforme David Crookall (2011) argumenta, a existência de um processo organizado de debrief e avaliação é um aspecto crucial para o aprendizado em jogos de simulação. 0 autor sustenta que é fundamental existir um momento que possibilite aos participantes uma reflexão sobre a experiência. Assim, enquanto "algum aprendizado normalmente ocorre no decorrer do jogo, 
as lições mais profundas são derivadas do debriefing"(Crookall, 2011, p. 908)5. Compartilhando de tal noção, a conclusão do "Jogo das Relações Públicas" foi concebida como um amplo processo avaliativo dotado de duplo objetivo: fomentar discussões que possibilitem o aprendizado dos participantes e fornecer subsídios para a pontuação dos estudantes na avaliação da disciplina. Nas aplicações-piloto, o jogo era mais do que um recurso didático auxiliar, constituindo uma atividade avaliativa para os estudantes. Nossa opção foi por não vincular a pontuação dos estudantes ao resultado das equipes no jogo em si, mas sim ao processo de debriefe avaliação, numa dinâmica que permitisse observar o aprendizado dos conteúdos mais importantes.

0 processo de avaliação é composto de três dimensões: as equipes se autoavaliam, elas avaliam as demais equipes e, por fim, avaliam o jogo enquanto recurso didático. 0 primeiro passo do processo ocorre após a finalização da terceira rodada, momento em que os participantes se reúnem em suas respectivas equipes e devem responder a um questionário elaborado para guiar a reflexão acerca dos quatro elementos fundamentais que apresentamos na sessão anterior. Esse questionário, entregue aos professores, opera como a base para a pontuação dos alunos, sendo complementado pelas discussões das próximas etapas do processo de avaliação.

Concluído o primeiro momento, inicia-se uma dinâmica coletiva de discussão na qual os principais elementos desenvolvidos no decorrer da atividade são retomados e analisados, com os estudantes oferecendo opiniões e impressões sobre sua experiência e sobre o desenrolar da simulação. Essa discussão é direcionada por questionamentos dos moderadores acerca das ações das equipes e das dinâmicas do jogo e suas temáticas, incentivando assim o debate entre os participantes.

Observamos nas aplicações-piloto a riqueza do momento de avaliação, no qual eram recorrentes as tentativas dos estudantes de vincular os acontecimentos do jogo com os conteúdos temáticos trabalhados, especialmente quanto às estratégias organizacionais e ao papel da mídia. Acreditamos ter sido exitosa a opção por trabalhar o jogo no decorrer da disciplina, permitindo múltiplas ligações entre os conceitos e a experiência da simulação. A condução do processo de avaliação é uma questão central, principalmente por perpassar um momento em que os participantes avaliam tanto suas próprias ações e estratégias, como também as táticas das demais equipes, movimento que só ocorre de fato quando os mesmos se despem do papel de jogadores para assumir o papel de estudantes. Essa análise permite observar a relação entre os diversos grupos sociais e influências mútuas entre os mesmos - desvelando, assim, aspectos de uma visão mais global. No geral, as seis aplicações geraram impressões semelhantes nos participantes, que avaliaram positivamente a atividade tanto pelo seu apelo lúdico quanto, principalmente, por permitir o aprendizado de determinados conceitos e uma percepção sobre a complexidade que configura a área. Mais ainda, foi possível constatar o alto engajamento dos alunos, observado tanto pelo nível de presença à aula nos dias de aplicação da atividade, como pelo interesse e expectativa no desenrolar da mesma.

Cada aplicação evidenciou ainda, na discussão final, elementos específicos para além dos quatro eixos temáticos. Os estudantes debateram, por exemplo, acerca do papel do poder econômico e político na disputa de sentidos, da importância de uma estratégia concisa e de objetivos claros, da existência de posicionamentos radicais e mediadores que eram assumidos por diversos grupos, da importância da retórica e do acionamento de diferentes valores nos discursos públicos das equipes, do recurso aos especialistas e da divergência sobre dados científicos no desenvolvimento de uma controvérsia. Rendeu, assim, reflexões e discussões de grande pertinência que contribuem para um aprendizado mais amplo sobre as relações públicas.

Concluídas as aplicações-piloto, o lançamento do "Jogo das Relações Públicas" ocorreu, por meio de um website ${ }^{6}$, no final de 2016. Com um cenário já disponível, a ideia é possibilitar que professores se apropriem gratuitamente da experiência e a ampliem, criando também um espaço para discussão e para a construção coletiva do jogo como um recurso didático relevante para o ensino de relações públicas. 


\section{REFERÊNCIAS}

ABT, Clark C. Jogos simulados: estratégia e tomada de decisão. Rio de Janeiro: José Olympio, 1974.

BALDISSERA, Rudimar. Significação e comunicação na construção da imagem conceito. Revista Fronteiras, v. 10, n. 3. 2008.

BARTON, Richard F. Manual de simulação e jogo. Petrópolis, RJ: Vozes, 1973.

BLUMER, Herbert. A massa, o público e a opinião pública. In: COHN, Gabriel (Org.). Comunicação e indústria cultural. São Paulo: Companhia Editora Nacional/Editora da Universidade de São Paulo, 1971.

BROUGÈRE, Gilles. A criança e a cultura lúdica. In: KISHIMOTO, Tizuko Morchida. O brincar e suas teorias. São Paulo: Pioneira Thomson Learning, 2002.

. Jogo e educação. Porto Alegre: Artes Médicas, 1998.

CROOKALL, David. Serious games, debriefing, and simulation: gaming as a discipline. Simulation \& Gaming, v. 41, 2011.

DEWEY, John. The public and its problems. Ohio: Swallow Press Books, 1954.

. Democracia e educação: introdução à filosofia da educação. 3. ed. São Paulo: Companhia Editora Nacional, 1959.

GAMSON, William. Games throughout the life cycle. Simulation \& Gaming, v. 44, 2013.

HENRIQUES, Márcio Simeone. Comunicação e mobilização na prática de polícia comunitária. Belo Horizonte: Editora Autêntica, 2010.

HENRIQUES, Márcio Simeone et al. Comunicação e estratégias de mobilização social. 2.ed. Belo Horizonte: Autêntica, 2004.

KISHIMOTO, Tizuko Morchida. O jogo e a educação infantil. São Paulo: Pioneira, 1994.

KUNSCH, Margarida M. Krohling. Planejamento de relações públicas na comunicação integrada. 4. ed. - rev., atual. e ampl. São Paulo: Summus Editorial, 2003.

PERROTTA, Carlo et al. Game-based learning: latest evidence and future directions. Research Report. National Foundation for Educational Research, April 2013.

PIAGET, Jean. Psicologia e pedagogia. Rio de Janeiro: Forense Universitária, 1976.

RAMOS, Cosete. Simulações e jogos para formação e treinamento de administradores. Brasília: Escola Nacional de Administração Pública, 1991.

TORO, José B.; WERNECK, Nísia M. D. Mobilização social: um modo de construir a democracia e a participação. 2.ed. Belo Horizonte: Autêntica, 2004.

Texto recebido em 12.01.2017 e aprovado em 28.06.2017. 